\title{
DA MODERNIDADE À PÓS-MODERNIDADE: EXPERIÊNCIAS E SIGNIFICADOS JUVENIS
}

\author{
Mara Regina Zluhan ${ }^{1}$ \\ Alexandre Vanzuita ${ }^{2}$ \\ Tânia Regina Raitz ${ }^{3}$
}

\begin{abstract}
Resumo
O presente artigo de revisão resgata alguns conceitos centrais da modernidade e da pósmodernidade para, a partir deles, analisar a condição juvenil nestes diferentes contextos. Os estudos têm demonstrado uma fragilidade acentuada no ensino médio , tanto no que tange a aprendizagem, quanto nos elevados índices de evasão e repetência. Dentre os diversos aspectos a serem investigados, um deles refere-se ao aprofundamento dos estudos acerca da juventude. Conhecer a trajetória juvenil ao longo da história é fundamental a todos os educadores e demais envolvidos com o processo educacional, tendo em vista que a compreensão dos projetos, anseios, fragilidades e sonhos dos jovens é necessária para romper com estigmas e rótulos que interferem negativamente na vida escolar, no seu ingresso no ensino superior e na inserção no mercado de trabalho. O entendimento de alguns pressupostos epistemológicos da modernidade e da pós-modernidade podem nos auxiliar como referencial teórico, para ampliar a compreensão sobre a trajetória juvenil.
\end{abstract}

Palavras-chave: Juventudes; Cultura Juvenil; Condição Juvenil; Modernidade; Pósmodernidade

\footnotetext{
1 Doutoranda, Universidade do Vale do Itajaí - Univali, Programa de Pós-Graduação em Educação, Departamento de Educação. Endereço: R. Uruguai, 458, Centro, CEP: 88302-901, Itajaí - Santa Catarina Brasil. Endereço eletrônico: mara.zluhan@avantis.edu.br.

2 Doutorando, Universidade do Vale do Itajaí - Univali, Programa de Pós-Graduação em Educação, Departamento de Educação. Endereço: R. Uruguai, 458, Centro, CEP: 88302-901, Itajaí - Santa Catarina Brasil. Endereço eletrônico: alexandre@ifc-camboriu.edu.br.

${ }^{3}$ Doutora e Docente do Programa de Pós-Graduação em Educação da Universidade do Vale do Itajaí - Univali, Departamento de Educação. Endereço: R. Uruguai, 458, Centro, CEP: 88302-901, Itajaí - Santa Catarina Brasil. Endereço eletrônico: raitztania@gmail.com.
} 


\section{INTRODUÇÃO}

É comum professores que atuam no Ensino Médio há algumas décadas se queixarem de que os alunos de hoje não são mais como no passado, e que a cada ano que passa a complexidade da docência se acentua, tendo em vista que estes não demonstram interesse pelo conhecimento, pela cultura escolar, bem como, têm muitas dificuldades para se identificar com a organização da escola e suas exigências, o que se reflete nos altos índices de reprovação, desistência e evasão. Esse descompasso entre a escola pensada no passado e a escola atual produziu o que hoje se discute amplamente: a crise no ensino médio.

Muito se tem pesquisado e refletido sobre esse nível de ensino, na tentativa de compreender os problemas e conflitos existentes. $\mathrm{O}$ presente artigo objetiva analisar uma das facetas desta complexa trama de questões, ou seja, a transição da juventude e seu processo escolar da modernidade para a pós-modernidade, a fim de verificar os componentes que atuam nessa nova configuração juvenil, trazendo à escola e aos professores elementos fundantes para realizar a discussão, que não pode se reduzir ao cotidiano escolar. Há que terse a visão da história, dos elementos que compõem a cultura juvenil, para que possamos ampliar nosso entendimento em busca de novas propostas educativas para a juventude.

\section{O PERCURSO DE FORMAÇÃO DA CULTURA JUVENIL NA MODERNIDADE}

Por longos períodos históricos a humanidade foi guiada pelos princípios da religião, das crenças e da espiritualidade e seus destinos eram guiados pelo peso da autoridade religiosa. Com o advento da modernidade, atribui-se à razão, à verdade e ao conhecimento o papel central na condução da história humana. A partir do racionalismo, o desenvolvimento da razão moderna se constituiu na principal forma de desenvolvimento moral e espiritual, por meio da superação do mundo do senso comum e das crenças tradicionais, buscando a liberdade e autonomia do homem.

O século XVI foi uma época de profundas transformações na sociedade ocidental, marcada por uma verdadeira explosão de descobertas. Esse movimento, que caracteriza a atmosfera intelectual do período chamado de Renascimento, trouxe consigo a rejeição das ideias até então aceitas e seguidas. Neste momento histórico, surgem duas grandes orientações metodológicas, abrindo as principais vertentes do pensamento moderno: a perspectiva do 
ZLUHAN, M. R.; VANZUITA, A. V.; RAITZ, T. R.

racionalismo, proposta por René Descartes e a perspectiva empirista proposta por David Hume.

O racionalismo privilegia a razão em detrimento da experiência do mundo sensível como via de acesso ao conhecimento. Este considera a dedução como o método superior de investigação filosófica. Descartes (1996) é o criador e impulsionador do racionalismo moderno, para ele o homem deve ser guiado pela razão.

Já na perspectiva empirista, a sabedoria é adquirida por percepções, pela origem das ideias, por onde se percebem as coisas, independente de seus objetivos e significados; pela relação de causa-efeito, por onde fixamos na mente o que é percebido, atribuindo à percepção causa e efeito. O empirismo afirma-se pela autonomia do sujeito, pela concepção da razão que não vê diferença entre o espírito e extensão, como propõe o racionalismo e ainda, pela matemática como linguagem, que assegura a inexistência de hipóteses. Para Hume (2006, s.p.), além da razão, os conhecimentos do homem são formados pelas suas experiências:

O homem é um ser racional e, como tal, recebe da ciência sua adequada nutrição e alimento. Mas os limites do entendimento humano são tão estreitos que pouca satisfação se pode esperar neste particular, tanto pela extensão como pela segurança de suas aquisições. O homem é um ser sociável do mesmo modo que racional..

Ao empirismo credita-se, por exemplo, a importância exagerada ao conhecimento técnico e prático. Ao racionalismo, sobretudo o pensamento cartesiano, recai a crítica de ser o responsável pela fracionamento no campo do saber. Ao estabelecer uma total distinção entre sujeito e objeto, Descartes abriu as portas para uma visão fragmentada da realidade e também do currículo escolar.

Neste momento da história, o mundo deixa de ser regido por uma ordem religiosa, a qual todos deveriam submeter-se, e passa a ser objeto da razão humana, que tenta construir sua própria ordem, com base na igualdade entre os homens, a liberdade de escolha, na capacidade de autocontrole. Franco (2011, p. 12) afirma:

\footnotetext{
No bojo dessas considerações, reside a concepção de indivíduos e jovens 'ideais' e a busca de suas emancipações com base no desenvolvimento de potencialidades isoladas. No entanto, tais pressupostos (entre outros), são absorvidos como norteadores de uma ordem coletiva. Ordem que não é mais uma ordem lograda, mas uma ordem a ser conquistada e vista como homogeneizadora e reguladora dos processos econômicos, políticos e sociais.
}

Neste cenário se desenvolveu a organização escolar brasileira, com o predomínio dos Colégios Jesuítas, que fundaram suas escolas em 1549, substituindo os preceptores e 
imprimindo um modo particular de educação, baseado no positivismo, cujas práticas eram fundamentadas em exames, competições, emulação e conquista de êxito. Essa metodologia transformou-se em modelo para outras instituições educacionais, que trataram de manter o formalismo pedagógico, no qual o ensino era completamente alheio à realidade, desvinculado das questões sociais, econômicas e estruturais da sociedade. Nesta ótica, a escola permanece protegida pelos seus muros e pela sua proposta pedagógica, com o objetivo de formar sujeitos aptos a se inserir na sociedade e contribuir com o seu desenvolvimento. Goergen (2006) ressalta que em relação a formação dos sujeitos, pretendia-se um ser forte, capaz de atuar sobre a realidade, pois possuía fundamentos e perspectivas estáveis para conquistar um futuro melhor

Desta forma, ao longo da trajetória da educação brasileira, as crianças e jovens que conseguiam ingressar no mundo escolar, tendo em vista que por longas décadas, a mesma se configurou de forma excludente e seletiva, precisavam se adequar a certas normatizações e regulações a fim de poderem se manter nele. $\mathrm{O}$ ensino, de caráter livresco, propedêutico, mantinha o professor no centro do processo e considerava a aprendizagem como o armazenamento das informações prontas, acabadas, através da memória.

O ensino consistia na transmissão do conhecimento, através da exposição de conteúdos organizados de acordo com a lógica do professor, ainda que sem significado para os alunos. A avaliação media o quanto das informações passadas foram retidas na memória pelos alunos e, assim a aprendizagem definia-se pelo estoque de informações acumuladas. Conforme afirma Silva (2000, p. 92):

As disciplinas foram técnicas de adestramento e individualização que pretendiam maximizar as forças dos indivíduos, otimizar seu rendimento e, ao mesmo tempo, extrair deles saberes e lhes conferir uma determinada natureza. $\mathrm{O}$ poder deixou de ser exterior aos indivíduos para fazer-se interior, ao processo de aprendizagem. [...] tenderam a desaparecer as penalizações exteriores, ao mesmo tempo em que a natureza que se conferia a cada aluno aparecia a cada vez mais como o resultado de suas próprias capacidades e aptidões.

A escola foi pensada para ser o centro do desenvolvimento racional, por meio das padronizações e dos métodos e, por conseguinte, para responder às necessidades e exigências do mundo do trabalho, utilizava-se de diversos recursos com a finalidade de levar a cabo o seu planejamento. A importância dada a algumas disciplinas pode ser um dos exemplos: a matemática, a aritmética, a geometria foram disciplinas valorizadas desde o início da organização curricular brasileira. Em alguns períodos, o enaltecimento da pátria e do regime republicano também foi alvo de valorização, levando para o interior das salas de aula 
ZLUHAN, M. R.; VANZUITA, A. V.; RAITZ, T. R.

disciplinas como EMC (Educação Moral e Cívica) ou OSPB (Organização Social e Política Brasileira). Durante muitos anos, segundo Rouanet (1987), os currículos extirparam aquilo que valorizasse os valores humanísticos.

Outra forma de garantir a formação da juventude era por meio das festividades e as comemorações das datas cívicas na escola. O calendário de datas comemorativas era amplamente divulgado e festejado, o que suscita uma digressão: o fato de ressaltar o valor e as contribuições dos negros, das mulheres, dos índios e demais grupos, não era uma garantia de transformar o olhar segregador e conservador que poderia permear a comunidade escolar, já que a experiência do homem branco, intelectualizado e economicamente estabelecido sempre foi o referencial da sociedade.

As festas escolares também eram consideradas importantes, à medida que iniciavam as crianças e jovens nas apresentações públicas, na oratória, na música, fazendo-as sentir o peso da aprovação ou reprovação social. O reconhecimento do público constituía-se em um importante elemento para a formação do seu caráter, impondo a necessidade de esmerar-se para obtê-lo.

Nas escolas do período moderno (séculos XVIII e XIX), as práticas disciplinares eram levadas a cabo pelas figuras do corretor, do censor/pretor ou do prefeito de estudos, que através de mecanismos específicos tratavam de formar indivíduos obedientes e dóceis. Tendo em vista que os alunos já vinham formados pela rigidez da cultura familiar, convivendo com valores como a formalidade nas relações, a severidade e obediência, essas questões refletiamse naturalmente no ambiente escolar, enrijecendo os comportamentos e reforçando simultaneamente os controles escolares e familiares.

O processo disciplinar permeava todas as ações e espaços da escola, e o próprio professor tratava de vigiar pessoalmente todos os gestos, palavras, olhares e movimentos dos alunos. Desta forma, atenção, respeito, assiduidade, silêncio e ordem eram palavras que constituíam o vocabulário diário de professores e alunos.

Os castigos físicos eram legalmente proibidos, mas os próprios pais autorizavam os professores a usá-los quando os seus filhos cometessem algum ato de indisciplina ou de desrespeito, outorgando-lhes irrestritos poderes em relação aos menores.

Ficar desocupado não fazia parte da filosofia da escola, sendo que o tempo e os espaços dos alunos eram regulados e reguladores para que não houvesse momentos de ociosidade. Para Foucault (1987) o sequestro do tempo dos alunos era uma prática muito comum, pois acreditava-se que, ocupando-se suas mentes e seus corpos com atividades 'saudáveis', aumentariam as chances de deixá-los livres de pensamentos mundanos e obscenos, educando- 
DA MODERNIDADE À PÓS-MODERNIDADE: EXPERIÊNCIAS E SIGNIFICADOS JUVENIS

os dentro dos princípios do trabalho, da dedicação e da ordem.

As razões do indivíduo deviam se submeter aos interesses coletivos e, por isso, a importância dos grupos como a família, a escola, a igreja, as associações, que desempenhavam um papel de grande relevância na vida dos jovens. Neste contexto pode-se recorrer a Kant, na Crítica da Razão Pura (1788) quando trata sobre o ideal do bem comum, da universalidade das ações morais entendidas como a superação dos interesses particulares. As atitudes, decisões e comportamentos eram regrados pelas condutas dos grupos e ter a anuência destes era fundamental para manter-se em equilíbrio nesse contexto.

Por isso, os jovens viviam cotidianamente sob o peso da autoridade, das normas e das leis, que eram consideradas vitais para manter o estabelecimento da ordem e da disciplina. Ser jovem durante a modernidade requeria a obediência servil aos estatutos reiterados pelas autoridades adultas, que não tinham preocupação em saber se estavam ou não adequados às expectativas e interesses juvenis.

O controle e a vigilância estava presente em diversos espaços e recursos escolares: na arquitetura, nos regimentos escolares, na figura do diretor, na coordenação, na forma como os alunos são dispostos em fileiras, pela sequência das aulas rigidamente divididas, pelo uniforme, pela forma tradicional de avaliação, enfim, são diversos componentes que tornam a rotina da escola permeada pelo poder disciplinar. Foucault (1987, p. 135) afirma que na escola: "Forma-se toda uma pedagogia analítica, muito minuciosa (decompõe até aos mais simples elementos a matéria de ensino, hierarquiza no maior número possível de graus cada fase do progresso) [...]"'.

Dessa forma, na sociedade moderna, houve a naturalização dos inúmeros instrumentos de regulação dispostos no cotidiano escolar e, por decorrência, a naturalização do disciplinamento. Essa disciplina que fabrica corpos dóceis, maleáveis e moldáveis articula-se com formas de ser e estar no mundo, permitindo que, cada um, naturalmente perceba e entenda o que é ser disciplinado e como ser disciplinado. Neste contexto, a prática pedagógica é analisada como uma prática disciplinar de normalização, de controle social, orientada para produzir sujeitos a partir de certas tecnologias de classificação e divisão, destacando-se os exames. Larrosa (APUD SILVA 2000, p. 76) destaca essa relação da seguinte forma:

Assim, da divisão simples e binária da inclusão-exclusão, do lícito e do ilícito, se passa as complexas formas de categorização do normal e do patológico, do anormal e do desviado, do normal ou do que excede ou não chega à forma. O normal se converte assim em um critério complexo de discernimento: sobre o louco, o enfermo, o criminoso, o pervertido, a criança escolarizada. 
ZLUHAN, M. R.; VANZUITA, A. V.; RAITZ, T. R.

A família também exercia um importante papel na manutenção das tradições, da moralidade, da ética, da transmissão de uma identidade social e familiar e da legitimidade quanto a valores já constituídos, permitindo assim aos jovens confrontarem-se com suas fragilidades e com os limites que são impostos pela vida em sociedade. A figura dos pais era revestida de uma autoridade natural, que raramente era questionada ou enfrentada e os filhos perseguiam o seu amor, procurando reconhecimento e aceitação. $\mathrm{O}$ medo, o respeito, o silêncio permeavam a relação de pais e filhos. As decisões dos filhos quanto a escolha profissional, namoro, casamento, lazer, passavam, necessariamente, pela autorização parental, que eram considerados como referências e modelos, mas havia também uma certa rebeldia, uma tentativa de distanciar-se. Pondera Szapiro e Resende (2010, p. 46):

O que importa aqui sublinhar é que a experiência de submissão que oferece a transmissão geracional é o que torna possível a simbolização, a tomada de posição, a aceitação, a negação, a construção do novo, a crítica ao antigo, enfim, a compreensão de que a condição humana é a de ter limites e de que esses limites não se constroem segundo o livre-arbítrio de cada um. As singularidades se constituem nos e a partir dos interditos.

Neste sentido, ser jovem é representar uma condição subjetiva de um tempo de transição e de aprendizado para a entrada no mundo dos adultos. Desta forma, as faixas etárias eram bem marcadas e cada etapa era revestida de características que lhe eram próprias e não poderiam ser negadas ou alteradas. Deve-se considerar, contudo, que existem formas distintas de caracterizar a juventude, ponderando-se que as categorias sociais foram divididas e subdivididas de diversas formas ao longo da história: infância, adolescência, juventude, jovem-adulto, adulto, maturidade, idoso, velho, terceira idade, quarta idade, de acordo com a cultura de cada época, os reconhecimentos legais, a prática cotidiana e os próprios princípios de regularidade que permeavam a modernidade.

Tais princípios estavam pautados na compreensão de ciência como definidora de uma verdade classificatória, categorizável e homogeneizadora. Nesse sentido, tanto Descartes (1596-1650), quanto Hume (1711-1776) e Kant (1724-1804) tiveram em suas teorias importantes contribuições. Seus pressupostos permearam a matriz epistemológica da maioria das ciências naturais, humanas e sociais.

Groppo (2000) refere-se à fase de ingresso na maturidade por meio de três divisões. Para o autor a medicina elaborou o conceito de puberdade, referindo-se às modificações corporais, a psicologia, a psicanálise e a pedagogia criaram o conceito de adolescência, referindo-se às mudanças na personalidade, na mente ou no comportamento, já a sociologia 
aborda as funções sociais na transição da infância para o mundo adulto. Bauman (2013, p. 44) apresenta outra relação:

[...] Primeiro veio a 'geração do baby boom', seguida por duas gerações denominadas $\mathrm{X}$ e $\mathrm{Y}$; mais recentemente [...] anunciou-se a iminente chegada da geração Z. Todas essas mudanças geracionais foram eventos mais ou menos traumáticos; em cada caso assinalaram uma quebra de continuidade e a necessidade de reajustes por vezes dolorosos, em função do choque entre as expectativas herdadas e aprendidas e as realidades imprevistas [...].

Chegar à fase adulta era um grande sonho, pois os jovens poderiam finalmente agir com autorregulação. Nessa transição da infância para a idade adulta era comum os momentos de revolta e luta juvenis. Motivos de frustração associados à dependência e à luta por ideias opostas às gerações anteriores, incitavam os comportamentos dos jovens em movimentos de subversão e crítica aos valores da época conforme Szapiro e Resende (2010). A juventude, na visão clássica, pode ser entendida como uma categoria social envolta com o engajamento nas lutas sociais e políticas, nos movimentos estudantis e na crítica ao sistema. De acordo com Franco (2011, p. 10):

\footnotetext{
Os levantes populares, principalmente os ocorridos em meados do século passado, foram saudados como rupturas contra regimes opressivos e injustos e como pontos de partida para a construção de sociedades socialistas, em que as desigualdades seriam eliminadas. Em todos eles os jovens tiveram papel de destaque, principalmente na Revolução Cubana (1959) e na dos Cravos (1974) em Portugal. No Brasil, foi expressiva a participação juvenil contra o Golpe do Regime Militar, nos idos dos anos 60 e 70 .
}

Quando Kant, em 5 de dezembro de 1783, escreve um artigo no qual faz a seguinte pergunta “O que é esclarecimento?" de certa forma dá ao jovens daquela época e também a todas as gerações que o sucederam uma nova visão em relação ao uso da razão. Segundo ele, “[...] o esclarecimento é a saída do homem de sua menoridade, que trata-se da incapacidade de fazer uso de seu entendimento sem a direção de outro indivíduo. O culpado dessa situação é o próprio indivíduo".

Kant (1783) afirma que é difícil para o homem sozinho livrar-se dessa menoridade, pois ela se apossou dele como uma segunda natureza. Aquele que tentar sozinho terá inúmeras dificuldades, pois seus tutores sempre tentarão impedir que ele experimente tal liberdade. No caso da juventude, essa tentativa pode levar aos atos de rebeldia, revolta e, em alguns casos extremos, de violência. 
ZLUHAN, M. R.; VANZUITA, A. V.; RAITZ, T. R.

Ter esclarecimento não é apenas adquirir um profundo conhecimento sobre um assunto, mas combinar isso com a conquista da autonomia. Nesse sentido, todos potencialmente podem esclarecer-se, já que possuem capacidade de pensar, mas no caso dos jovens, a conquista da autonomia se mostra mais complexa, pois a unidade de pensamentos, atitudes e normatizações em que estão imersos, dificulta o processo de libertação das amarras cognitivas e sociais que lhes são impostas.

A busca pelo esclarecimento na concepção kantiana é um ato de coragem, que implica no desenvolvimento pessoal, para posteriormente, afetar a existência social e política de todos os homens. Há um deslocamento da função intelectual dos políticos, das universidades, dos livros, dos dirigentes espirituais e de todas as demais formas de manter a tutela da sociedade, para transferi-la ao próprio homem, que necessita mudar sua mentalidade para adquirir a liberdade de expressão.

Utilizar a razão é diferente de utilizar a liberdade de consciência, se trata do uso público e privado da razão, já que a mesma pode ser livre no seu uso público e submissa no seu uso privado. Por isso, Kant (1783) pede que não se pratique uma desobediência cega e estúpida, mas que se faça um uso adaptado da razão, conforme a circunstância. Para ele o esclarecimento não existe somente quando há garantia pessoal de pensamento, mas quando há sobreposição do uso universal, do uso livre e do uso público da razão (FOUCAULT, 1993).

O aluno da modernidade, ao buscar o esclarecimento, o fazia na certeza da durabilidade, da permanência e da emancipação. Os conceitos elaborados ao longo da sua trajetória educacional eram levados para a vida profissional, que também configurava-se de forma estável e duradoura. A própria vida e o futuro eram bastante previsíveis, e se podiam fazer planos definidos e determinados, com base na persistência. Para Goergen (2006, p. 599) " [...] o esclarecimento não deve ser considerado como uma teoria, mas uma prática e uma ação comum aos seres humanos, devendo, pela mesma razão, estar intimamente ligado a um projeto educativo".

Os problemas, as ansiedades e os sofrimentos juvenis não eram resolvidos por meio do consumismo desenfreado e suas armadilhas ou com o suprimento exagerado de todas as coisas. Os jovens aprendiam a resolver seus dilemas das mais diversas formas, sem buscar em fontes externas a solução para os seus conflitos. A frustração, a raiva, a revolta eram sentimentos que precisam ser vividos e, por isso, os pais não buscavam estratégias para poupar os filhos dessas emoções.

A perspectiva de um futuro certo, planejado e redentor levava os jovens, sujeitos autores, a percorrerem trajetórias uniformes e pré-definidas, com muita determinação e 
DA MODERNIDADE À PÓS-MODERNIDADE: EXPERIÊNCIAS E SIGNIFICADOS JUVENIS

sacrifício, viabilizando o alcance dos seus sonhos e projetos e a permanência neles até o final da vida. Com a crise das narrativas legitimadoras, notadamente no final do século XX, abre-se espaço para a possibilidade, para a diferença, no qual o futuro é aqui e agora. Substitui-se a uniformidade pela polissemia, na qual hierarquia e fronteiras se diluem, permeadas pelo desenvolvimento das tecnologias. Está posto um novo tempo, que define a alteração do estatuto do saber, da crise da ideia da filosofia, relativizando as certezas e as utopias. É chegada a pós-modernidade.

\section{A CONDIÇÃO JUVENIL NA PÓS-MODERNIDADE}

A busca pela autonomia e liberdade vai lentamente se configurando na história da humanidade, à medida que o homem distingue o seu papel, enquanto indivíduo, nesse processo. Concomitantemente ao reconhecimento das singularidades e individualidades vão se firmando novos pensamentos, que passam a apresentar formas distintas de explicações para o sentido da vida, do homem e do conhecimento. A partir do final do século XX (anos 1960 e 1970) alguns autores começam a declarar o fim das ideias iluministas, indicando o surgimento de uma nova era, a pós-modernidade.

Os pós-modernistas rompem com a ideia de história, enquanto substância que nos define. Assim, não eliminam o passado, mas o presente é a fonte de explicação de todas as coisas. O acontecimento presente é reversível, e propõe as rupturas e descontinuidades, adotando uma perspectiva individual e não universal. Jean-François Lyotard (1924 -1998), filósofo francês, publicou em 1979 a obra "A condição Pós- Moderna" e iniciou um intenso debate acerca dos dois grandes relatos da modernidade: o relato da emancipação e o relato especulativo. O estudo de Lyotard (1990, p. 3) teve por objeto a posição do saber nas culturas pós-modernas, afirmando que "[...] o saber muda de estatuto ao mesmo tempo que as sociedades entram na idade dita pós-industrial e as culturas na idade dita pós-moderna”.

Após a Segunda Guerra Mundial estabelece-se um declínio quanto à legitimação do saber, efeito do desenvolvimento das técnicas e das tecnologias. A crise do saber científico procede da erosão interna do princípio de legitimação do saber. Esta erosão opera no jogo especulativo, e é ela que, ao afrouxar a trama enciclopédica na qual cada ciência devia encontrar seu lugar, deixa-as se emanciparem. Assim, conforme Lyotard (1990), se o discurso da ciência não pode ser tido como verdadeiro, porque tudo é um jogo de linguagem, o 
ZLUHAN, M. R.; VANZUITA, A. V.; RAITZ, T. R.

discurso da emancipação (defendido por Kant, por exemplo), não pode ser verdadeiramente justo, na medida em que é guiado por aquele saber científico.

Como consequência da deslegitimação do saber, a ciência não pode mais legitimar a si mesma e nem a outros jogos de linguagem; os jogos de linguagem dissolvem o sujeito e tornam a linguagem o vínculo social; o fracasso da filosofia especulativa moderna como discurso de legitimação e sustentação do projeto emancipatório; a transformação dos sábios em cientistas com um saber fragmentário; a filosofia especulativa humanista assume o estudo da lógica ou da história das ideias; há o surgimento de um pessimismo generalizado, pois ninguém domina todos os jogos de linguagem e não há uma meta-língua universal (LYOTARD, 1990).

Muitas mudanças começam a ocorrer na forma de caracterizar a juventude a partir desse período, iniciando com as definições cronológicas. Melucci; Fabbrini (1992, APUD DAYRELL, 2003) defendem que as mudanças físicas e psicológicas ocorridas na juventude não podem ser analisadas somente pelo viés biológico, pelo contrário, são muito variadas e diretamente influenciadas pelas condições sociais, culturais, de gênero e de regiões geográficas. Existem diversos sinais corporais e psicológicos que acenam para o início da juventude, entre eles a procriação, o desejo de menos proteção da família, quando o jovem busca a independência e assume novas responsabilidades. O autor faz uma importante análise dos fenômenos evolutivos que cercam a juventude, afirmando que as mudanças não são lineares e tampouco as experiências atuais suprimem as anteriores, pois muitas dessas transformações irão acompanhar o indivíduo ao longo da sua vida, caracterizando a juventude não como uma simples passagem, mas como parte do processo constitutivo de cada sujeito.

A partir de então, os jovens da era pós-moderna passam a viver uma nova lógica de construção do conhecimento em decorrência de uma reorganização nas delimitações clássicas dos campos científicos, nos quais as disciplinas desaparecem, surgem novos campos de conhecimento e estes são diretamente transversalizados com a evolução tecnológica. $\mathrm{O}$ conhecimento passa a ser visto como uma mercadoria, um valor, que será produzido para ser vendido e todo o conhecimento produzido deverá ser traduzido para a linguagem das máquinas.

Lyotard (1990) afirma que por meio do desenvolvimento das tecnologias, a partir da Segunda Guerra Mundial, os grandes relatos perderam sua credibilidade. Para o autor, as técnicas, que tem por função receber dados ou agir sobre um contexto, são diretamente afetadas pela otimização das performances. Todo o conhecimento produzido passará por um 
processo de administração das provas e de verificação de enunciados, porém, esse processo de performance é diretamente influenciado pela riqueza, pelos interesses e pelo poder. Lyotard (1990, p. 80) discorre sobre:

[...] aumento do output (informações ou modificações obtidas), diminuição do input (energia despendida) para obtê-las. São estes, pois, os jogos cuja pertinência não é nem o verdadeiro, nem o justo, nem o belo, etc., mas o eficiente: um 'lance' técnico é 'bom' quando é bem sucedido e/ou quando ele despende menos que um outro

Na sociedade pós-moderna, o impacto das tecnologias na configuração da cultura juvenil passa a ser intenso, considerando-se que a internet, as redes sociais, os telefones celulares, a TV, entre outros, ocupam um lugar central na vida de seus usuários. $\mathrm{O}$ mundo virtual desencadeou uma série de modificações no cotidiano do jovem, no que tange as suas relações, no contato com as informações, na forma de aprender, de produzir significados e conhecimentos. Para muitos a utilização da memória foi transferida do cérebro para os pendrives e servidores externos.

Para Garbin (2009) a "geração net" transita com propriedade entre chats, e-mails, sites, blogs, webzines, ao mesmo tempo em que vê TV, troca de canal, comenta o que viu, ouve música, enfim, utiliza simultaneamente diversos recursos tecnológicos. Esses espaços se configuram também como importantes recursos no sentimento de pertencimento dos jovens, atribuindo significados aos seus fazeres e transformando-se em um importante meio de expressividade e maneiras de ser e estar no mundo.

As crescentes necessidades impostas pela lógica do capitalismo, impele cada vez mais precocemente os jovens para o mundo do trabalho. A grande maioria dos alunos de escola pública necessita alinhar sua vida escolar com atividades laborais, já que uma parcela da juventude desde muito cedo assume o status de adulto. São aqueles que ingressam precocemente no mundo do trabalho e são chamados a desempenhar tarefas e assumir comportamentos e responsabilidades (produtiva, conjugal, doméstica, parental) do mundo adulto. Nestes casos, o salário é fundamental para contribuir no orçamento doméstico.

Geralmente a elevada carga horária de trabalho os impede de dedicar um tempo mínimo às exigências escolares, refletindo negativamente no seu desempenho. Em muitos casos, a própria família não destina o valor necessário à educação, preferindo que o jovem trabalhe e ajude no pagamento das despesas familiares, não motivando a sua permanência na escola. De acordo com a Agenda Juventude Brasil (2013) o trabalho fez ou faz parte da experiência de vida de 4 em cada 5 jovens brasileiros, o que nos leva a afirmar que a juventude brasileira é 
ZLUHAN, M. R.; VANZUITA, A. V.; RAITZ, T. R.

uma juventude trabalhadora. Por outro lado, a pesquisa demonstra que houve um acréscimo na escolaridade, já que 59\% estão no Ensino Médio e 39\% já concluíram esse nível de ensino. Frigotto (2009, p. 25) ressalta:

Todos esses grupos têm suas especificidades, mas do ponto de vista psicossocial e cultural, tendem a sofrer um processo de adultização precoce. A inserção no mercado formal ou 'informal' de trabalho é precária em termos de condições e níveis de remuneração. Uma situação, portanto, muito diversa da dos jovens de 'classe média' ou fillhos dos donos de produção, que estendem a infância e a juventude.

Diante da condição de provisoriedade e das incertezas impostas pela pós-modernidade, o jovem convive cotidianamente com a ameaça de ficar para trás, de ser excluído do jogo, de ser incapaz de atender as novas exigências e demandas. Essa ansiedade constante, em muitos casos, leva a uma perda de perspectiva de futuro, invadindo o presente e gerando uma certa imobilidade diante dos fatos. Segundo Bauman (2013, p.22):

[...] nada nesse mundo se destina a durar, que dirá para sempre. Objetos hoje recomendados como úteis e indispensáveis tendem a 'virar coisa do passado' muito antes de terem tempo de se estabelecer e se transformar em necessidade ou hábito. Nada é visto como estando aqui para sempre, nada parece insubstituível. Tudo nasce com a marca da morte iminente e emerge da linha de produção com o 'prazo de validade' impresso ou presumido [...].

As formas de sociabilidade também se modificaram, a começar pelo desenvolvimento das cidades. Se antes as crianças e jovens cresciam interagindo com os seus vizinhos, estabelecendo laços duradouros de amizade com colegas da rua, deslocando-se livremente por diversos bairros, visitando parentes aos finais de semana, hoje, em função do crescimento desordenado, da violência, dos congestionamentos, do excesso de atividades, as pessoas tendem a limitar suas interações sociais, preferindo isolar-se na segurança dos seus lares, restringindo, dessa forma, o convívio social, portanto Ganclini (2011, p. 286) salienta que,

A violência e a insegurança pública, a impossibilidade de abranger a cidade (quem conhece todos os bairros de uma capital?) levam a procurar na intimidade doméstica, em encontros confiáveis, formas seletivas de sociabilidade. Os grupos populares saem pouco de seus espaços, periféricos ou centrais; os setores médios e altos multiplicam as grades nas janelas, fecham e privatizam ruas do bairro. Para todos o rádio e a televisão, para alguns o computador conectado para serviços básicos, transmitem-lhes a informação e o entretenimento a domicílio.

O enfraquecimento e a deteriorização dos vínculos se estendem à família, cujos pais estão cada vez mais atarefados com suas exigências profissionais e transferem para às 
tecnologias e para os presentes de finais de semana a sua compensação pela ausência no cotidiano dos filhos. São raros os momentos de compartilhamento, de trocas, de diálogo.

Podemos falar que os jovens vivem uma crise de referências, na qual se abandonam os princípios da polidez e da civilidade, o sentido da história, o interesse pela política, os conhecimentos sobre literatura, religião, arte, a fim de poder viver neste caos que se lhes apresenta. Talvez essa "confusão" também tenha sido sentida pelos jovens da modernidade, quando lhes foi dito que Deus não era o responsável por todas as coisas e que o mundo não era perfeito e acabado. Atualmente, uma boa saída para esses momentos de conflito encontrase nos shoppings centers, que substituem as praças, ruas e os colégios do passado. Além de terem se convertido no templo máximo do consumismo, se transformaram num importante ponto de encontro dos jovens, no qual eles buscam um sentimento de pertencimento, a impressão de fazerem parte de uma comunidade conforme Bauman (2001).

O jovem se depara com muitos espaços vazios de significados: aeroportos, autoestradas, transportes públicos, ruas, praias. São locais que mantém circulação intensa de pessoas, mas é como se todos fossem invisíveis ao olhar alheio. O antigo preceito adulto "não fale com estranhos" se tornou norma. E nesse sentido as relações interpessoais vão progressivamente sendo corroídas pela individualização, pelo narcisismo, pelos interesses próprios. Bauman (2001, p. 111) aprofunda essa realidade ressaltando que:

[... ] uma cidade é um assentamento humano em que os estranhos têm chance de se encontrar. [...]. Os estranhos se encontram numa maneira adequada a estranhos; um encontro de estranhos é diferente de encontros de parentes, amigos ou conhecidos parece, por comparação, um "desencontro". No encontro de estranhos não há uma retomada a partir do ponto em que o último encontro acabou, nem troca de informações sobre as tentativas, atribulações ou alegrias desse intervalo, nem lembranças compartilhadas: nada em que se apoiar e que sirva de guia para esse encontro. $\mathrm{O}$ encontro de estranhos é um evento sem passado. Frequentemente também é um evento sem futuro [...].

A superficialidade das relações se reflete na forma como os jovens configuram sua vida. Flexibilidade e mudanças atuam como vetores de felicidade. O namoro se transformou em "pegar/ficar", os casamentos tornaram-se raros, e quando se efetivam, tem curto prazo de duração, pois frente à menor frustração a relação é rompida. A banalização do sexo é evidente, não há mais a necessidade do flerte, do namoro, da aprovação do parceiro, da conquista. Após alguns encontros, o encanto acaba e fica o vazio, até o encontro do próximo parceiro. Em alguns casos, o vazio e a frustração podem levar a problemas como a bulimia, anorexia, abuso de drogas, depressão e ataque de pânico, transtornos crescentemente encontrados na população juvenil. 
ZLUHAN, M. R.; VANZUITA, A. V.; RAITZ, T. R.

A mesma flexibilidade das relações é levada ao mercado de trabalho, às amizades, às preferências musicais, enfim, a vida tornou-se um grande panóptico, porém, as posições foram invertidas, e agora muitos olham para um, consolidando a sociedade do espetáculo, no qual as pessoas estão prontas a expor-se da forma mais impactante e inesperada possível, na busca de novas emoções, novos amores e sensações. O que vale é o presente, é o acontecimento. A história ficou para trás, numa contradição extrema com os jovens da modernidade, que viam na tradição, na linearidade, na previsão os fundamentos da sua vida alguma possível segurança, contudo Bauman (2001, p. 101) acentua que:

[...] Mudamo-nos agora, de uma sociedade do estilo Panóptico para uma sociedade do estilo sinóptico: as mesas foram viradas e agora são muitos que observam poucos. Os espetáculos tomam o lugar da supervisão sem perder o poder disciplinador do antecessor. A obediência aos padrões (uma maleável e estranhamente ajustável obediência aos padrões eminentemente flexíveis, acrescento) tende a ser alcançada hoje em dia pela tentação e pela sedução e não mais pela coerção - e aparece sob o disfarce do livre-arbítrio, em vez de revelar-se como força externa.

Rouanet (1987) destaca que é comum entre os professores o estereótipo das gerações atuais como sendo desinteressadas pelo contexto social, individualistas e alienadas, numa tendência a compará-las às gerações anteriores, mitificadas como gerações mais comprometidas e generosas. Porém, esse discurso precisa ser revisado após as manifestações de junho de 2014, quando assistimos no Brasil milhares de jovens, nas praças, nas ruas, nas redes sociais demonstrando indignação, ousadia e esperança, num misto de vozes, vibrações, exigências e lutas. Quem eram aqueles jovens? Será que eles aprenderam sobre cidadania, lutas sociais, exclusão e diversidade na escola? Ou eles participaram de mais um espetáculo, com oportunidades para muitos "selfies" e curtidas no Facebook? Estes e outros tantos questionamentos acerca das especificidades da juventude, dos movimentos jovens, do protagonismo juvenil, não podem mais ser ignorados pela escola, o que nos leva a considerar que essa deva ser uma preocupação crescente das políticas públicas, a fim de buscar respostas para a crise educacional que se vive hoje no país.

\section{CONSIDERAÇÕES FINAIS}

A trama de desenvolvimento juvenil é tecida em meio a uma multiplicidade de contextos e possibilidades e vem se expandindo, ampliando a visibilidade dos jovens neste 
DA MODERNIDADE À PÓS-MODERNIDADE: EXPERIÊNCIAS E SIGNIFICADOS JUVENIS

século XXI e apresentando uma crescente variabilidade na determinação das fronteiras que marcam a passagem para o mundo adulto.

As transformações trazidas pela pós-modernidade têm atingido a juventude brasileira de diversas formas, imprimindo-lhe características muito distintas do jovem da modernidade. Ao lado de demanda por maior escolaridade, por melhor formação para o trabalho ou para a vida, há a diminuição absoluta da oferta de empregos. Ao mesmo tempo, faltam espaços sociais e de vivência cultural, sendo a escola pública, de certa forma, um dos únicos espaços públicos que restaram, pois a urbanização acelerada não foi acompanhada de investimentos públicos em equipamentos sociais e culturais. A iniciativa privada assumiu, em função de seus interesses, a criação de áreas de convívio, como shopping centers, concebidos para o consumo, mas que, por isso, promovem mais facilmente a segregação econômica que a vivência cultural coletiva, não sendo espaços públicos, portanto.

Se na modernidade a escola secundária era destinada aos poucos privilegiados, filhos de pessoas influentes e de posses, atualmente, as políticas de expansão do Ensino Médio conseguiram garantir o número de vagas necessário para atender a juventude brasileira, porém, o grande desafio está em possibilitar a permanência desses jovens na escola. Os altos índices de reprovação e evasão neste nível de ensino demandam de ações imediatas do Estado, a fim de que os 10.580.060 jovens na idade entre 15 e 17 anos (Censo Escolar da Educação Básica, 2012), possam se qualificar para potenciais empregos, para o trabalho autônomo, para o acesso ao ensino superior, ou simplesmente em busca de convívio social e cultural. Cada um desses anseios constitui, por si só, um direito indiscutível, mas que nem sempre é reconhecido por escolas, cujo projeto pedagógico foi concebido noutras circunstâncias e para outro público, e que hoje estão em descompasso com sua própria constituição social.

Parece que a sociedade, e por consequência, a escola, não estão dando conta das dimensões humanas da nossa época, e conceitos como solidariedade, justiça, tolerância, felicidade, entre outros, estão muito distantes da realidade juvenil. A informática, de uma maneira geral, é mais utilizada para manter vínculos afetivos e amorosos, do que para a construção do conhecimento. Na modernidade estes valores eram amparados pela razão, e o otimismo em relação a um futuro melhor favorecia a vivência cordial entre os pares.

Se os jovens da modernidade podiam contar com uma história e com um projeto de liberdade e justiça, a juventude da pós-modernidade se vê desacreditada na humanidade e na sua ambição de progresso, tendo em vista a miséria, a fome, as guerras, a destruição ambiental e tantos outras tragédias que colocam em risco o progresso histórico, o sujeito 
ZLUHAN, M. R.; VANZUITA, A. V.; RAITZ, T. R.

autônomo e os valores laicos, tidos como fundamentais para garantir uma sociedade mais justa e uma vida melhor.

As práticas pedagógicas escolares continuam pautadas nos grandes metarrelatos, destacando o papel da razão e do conhecimento, fatores estes que mantém a sua permanência e reconhecimento. Porém, que conhecimento é este tão facilmente transformado em mercadoria? Por que nas escolas ainda vivemos a competitividade ao invés da cooperação? Por que a organização curricular continua esquadrinhada e fragmentada? Por que as relações interpessoais são pautadas na individualidade, promovendo a coisificação do homem pela ciência e pela técnica? Diante de tantas dúvidas e paradoxos, talvez o equilíbrio entre a tradição, o presente e o futuro possa revelar-se como uma proposta de emancipação e de formação do sujeito, levando em conta as multiplicidades e pluralidades que integram o mosaico juvenil.

\title{
OF MODERNITY TO POSTMODERNISM: EXPERIENCES AND MEANING YOUTH
}

\begin{abstract}
The present review aims to rescue some central concepts of modernity and post-modernity, from them, analyze the condition of youth in these different contexts. Studies have shown a marked weakness in high school, both in terms of learning, as the high dropout and repetition rates. Among several aspects to be investigated, one of them refers to deeper studies about youth. Meet juvenile trajectory throughout history is fundamental to all educators and others involved with the educational process, taking into account that understanding of projects, desires, weaknesses and dreams of young people is needed to break stigmas and labels that negatively interfere with school life, in their entry into higher education and entering the labor market. The understanding of some epistemological assumptions of modernity and postmodernity can help us as a theoretical framework to broaden the understanding of juvenile trajectory.
\end{abstract}

Key-words: Youth; Youth Culture; Youth Condition; Modernity; Postmodernity 


\title{
DE LA MODERNIDAD A LA POSMODERNIDAD: EXPERIENCIAS Y SIGNIFICADOS DE LOS JÓVENES
}

\begin{abstract}
Resumen
El presente artículo de revisión rescata algunos conceptos centrales de la modernidad y posmodernidad, a partir de ellas, para analizar la situación de los jóvenes en estos contextos diferentes. Los estudios han demostrado una marcada fragilidad en la escuela secundaria, tanto en términos de aprendizaje, ya que en elevados niveles de elusión y la repetición. Entre los diversos aspectos que deben ser investigados, uno de ellos se refiere a la profundización de los estudios sobre la juventud. Conocer la trayectoria de los jóvenes a lo largo de la historia es fundamental para todos los educadores y otros involucrados en el proceso educativo, teniendo en cuenta que el entendimiento de los proyectos, las angustias, las debilidades y los sueños de los jóvenes es necesario romper con los estigmas y etiquetas que interferir negativamente en la vida escolar, en su ingreso a la educación superior y la inserción en el mercado laboral. La comprensión de algunos supuestos epistemológicos de la modernidad y post-modernidad pueden ayudarnos como referencia teórica a ampliar la comprensión de la trayectoria de la juventud.
\end{abstract}

Palabras claves: Juventud; Cultura juvenil; Condición juvenil; Modernidad; Post-modernidad

\section{REFERÊNCIAS}

BAUMAN, Sygmund. Modernidade líquida. Rio de Janeiro: Zahar, 2001. 2013.

. Sobre juventude e educação: conversas com Ricardo Mazzeo. Rio de Janeiro: Zahar,

BRASIL. Pesquisa agenda juventude Brasil: pesquisa nacional sobre perfil e opinião dos jovens brasileiros 2013. Brasília, DF: 2013. Disponível em:

<http://juventude.gov.br/participatorio/participatorio/agenda-juventude-brasil-veja-versaoatualizada\#.WA6G8Vd0LCc>. Acesso em: 13 de Fev. 2014.

. Instituto Nacional de Estudos e Pesquisas Educacionais Anísio Teixeira. Censo da educação básica - 2012. Brasília, DF: 2013. 
ZLUHAN, M. R.; VANZUITA, A. V.; RAITZ, T. R.

CANCLINI, Néstor García. Culturas híbridas. 4. ed. São Paulo: Editora da Universidade de São Paulo, 2011.

DAYRELL, Juarez. O jovem como sujeito social. Revista Brasileira de Educação, Rio de Janeiro: ANPEd, n. 24, Set /Out/Nov/Dez, 2003. http://dx.doi.org/10.1590/S141324782003000300004

DESCARTES, René. Discurso do Método. São Paulo: Martins Fontes, 1996. Disponível em: <http://www.josenorberto.com.br/DESCARTES_Discurso_do_método_Completo.pdf〉. Acesso em: 24 de Out. 2016.

FOUCAULT, Michel. Vigiar e punir: nascimento da prisão. 24. ed. Petrópolis, RJ: Vozes, 1987.

Qué es la Ilustración? Revista Internacional de Filosofia, n. 7, p. 5-18, 1993.

FRIGOTTO, Gaudêncio. Expectativas juvenis e identidade no Ensino Médio: Ensino Médio no Brasil - "juventudes" com futuro interditado. In: Juventude e escolarização: os sentidos do Ensino Médio. Salto para o Futuro. Brasília, DF: Ano XIX, boletim 18, 2009.

GARBIN, Elisabete Maria. Conectados por um fio: alguns apontamentos sobre internet, culturas juvenis e contemporâneas e escola. In: Juventude e escolarização: os sentidos do Ensino Médio. Salto para o Futuro. Brasília, DF: Ano XIX, boletim 18, 2009.

GROPPO, Luís Antonio. Juventude: ensaios sobre sociologia e história das juventudes modernas. Rio de Janeiro: Difel, 2000.

GOERGEN, Pedro. Questões im-pertinentes para a filosofia da educação. Educação $e$ Pesquisa, São Paulo: Faculdade de Educação da Universidade de São Paulo, v. 32, n. 3, set./dez. 2006. http://dx.doi.org/10.1590/S1517-97022006000300011

HUME, David. Investigação acerca do entendimento humano. Versão eletrônica. Tradução: Anoar Aiex. Edição: Acrópolis. Disponível em:

$<$ http://docente.ifrn.edu.br/rodrigovidal/disciplinas/epistemologia-da-ciencia-2012.2/texto-dedavid-hume-investigacao-acerca-do-entendimento-humano/view>. Acesso em: $10 \mathrm{de} \mathrm{Jul.}$ 2014.

KANT, Immanuel. O que é esclarecimento? Disponível em: <http://coral.ufsm.br/gpforma/2senafe/PDF/b47.pdf>. Acesso em: 26 de Jun. 2014.

LYOTARD, Jean-François. O pós-moderno. 3. ed. Rio de Janeiro: José Olympio Editora, 1988.

ROUANET, Sergio Paulo. As razões do iluminismo. São Paulo: Companhia das Letras, 1987.

SILVA, Tomaz Tadeu da. (Org.). O sujeito da educação: estudos foucaltianos. 6. ed. Rio de Janiero: Vozes, 2000. 
DA MODERNIDADE À PÓS-MODERNIDADE: EXPERIÊNCIAS E SIGNIFICADOS JUVENIS

SZAPIRO, Ana Maria.; RESENDE, Camila Miranda de Andrade. Juventude: etapa da vida ou estilo de vida? Psicologia \& Sociedade, Belo Horizonte: Associação Brasileira de Piscologia Social, v. 22, n. 1, 2010. Disponível em:

<http://www.scielo.br/pdf/psoc/v22n1/v22n1a06.pdf>. Acesso em: 28 de Dez. 2016.

Data de recebimento: $12 / 04 / 2016$

Data de aceite: 02/12/2016 